\title{
High Efficient Resonant DC-DC Converter for Automotive LED Driver Applications using Phase Shift Control Strategy
}

\author{
Syed Simran.K ${ }^{1} \mid$ Md.Anwar ${ }^{2} \mid$ Dr.Sharan Reddy ${ }^{3}$ Santosh.B.M ${ }^{4}$
}

${ }^{1}$ PG Scholar, Electrical and Electronics Engineering, Ballari Institute of Technology and Management, Ballari, Karnataka, India.

${ }^{2}$ Assistant Professor, Electrical and Electronics Engineering, Ballari Institute of Technology and Management, Ballari, Karnataka, India.

3Professor, Electrical and Electronics Engineering, Ballari Institute of Technology and Management, Ballari, Karnataka, India.

${ }^{4}$ Assistant Professor, Electrical and Electronics Engineering, Ballari Institute of Technology and Management, Ballari, Karnataka, India.

To Cite this Article

Syed Simran.K, Md.Anwar, Dr.Sharan Reddy and Santosh.B.M. High Efficient Resonant DC-DC Converter for Automotive LED Driver Applications using Phase Shift Control Strategy. International Journal for Modern Trends in Science and Technology 2021, 7, pp. 01-07. https://doi.org/10.46501/IJMTST0710001

\section{Article Info}

Received: 30 August 2021; Accepted: 26 September 2021; Published: 27 September 2021

\section{ABSTRACT}

A high frequency DC-DC converter operating in the $\mathrm{MHz}$ range is proposed, which can achieve unbiased load current even while maintaining high performance over a wide range of load voltages. Due to these functions, the provided transformer is suitable for LED driver applications, which require different types of LEDs to operate with controlled current. The proposed transformer satisfies the uncontrolled load current using the LCL-T resonance community and achieves high efficiency using a predetermined switching frequency. The LCL-T resonance transformer also works effectively in controlling its output to the required rating using phase shift control. The overall performance of the LCL-T Echo transducer was evaluated and compared with the LC3L controlled echo transducer. Simulation work is done using the MATLAB / Simulink program.

KEYWORDS: DC-DC converter, LCT-T, Simulink, Transformer, MOSFET switch.

\section{I.INTRODUCTION}

LEDs (light emitting diodes) are gradually becoming the accepted answer in automated lighting programs, allowing their highest power management, extended life, faster operating and reversal efficiency and additional lease of fresh materials the current LED era. To enable higher luminance performance, LEDs carry out moderate monochrome up to $60 \mathrm{~lm} / \mathrm{W}$ on AlInGaP devices (from yellow to magenta instruments) and 100 $\mathrm{lm} / \mathrm{W}$ on InGaN devices (from blue to green and white devices), with the advantage that tedious low performance Filters, the briefest alert length, right on the money (mainly energizing for brake lights) and the longest run, achieving 50,000 hours of $30 \%$ radiant exhaust, making the help life of the vehicle much better. This can be achieved using PWM (pulse width modulation) or analog current control with LEDs. But due to the increased hexagonal characteristics, the LEDs drive a well-controlled current day. Since LED coloring and brightness are related to their forward current, the LED must be pushed with regular synchronization to avoid changing the phase angle and maintaining 
uniform brightness. In fashion, the LED series has processes to maintain a consistent present day. The first is the continuous transfer mode in the modern view. It receives high current (in percentage) or advanced hysterical control (HCC) processing to adjust the speech. As the transfer case develops inside, the performance will be higher. But its problems are big waves, strong radioactive infiltration and coffee grounds. The alternative method is precisely controlled fixed width. It controls the latest technology by adjusting the gate voltage of electrical MOSFETs through excellent note handling. In contrast to switch-mode regulator, micro-regulation is more precise and solid, but less environmentally friendly. In addition, in automotive software, the total range of LEDs in the series is wide, resulting in a wide variety of output voltages. Therefore, power transformers using LEDs must provide a constant load current over a variety of output voltages.The loss minimizing control method leads to efficiency improvements over wide operating range when applied to the wide range LCL-T (WR-LCL-T) converter shown in Fig. 1

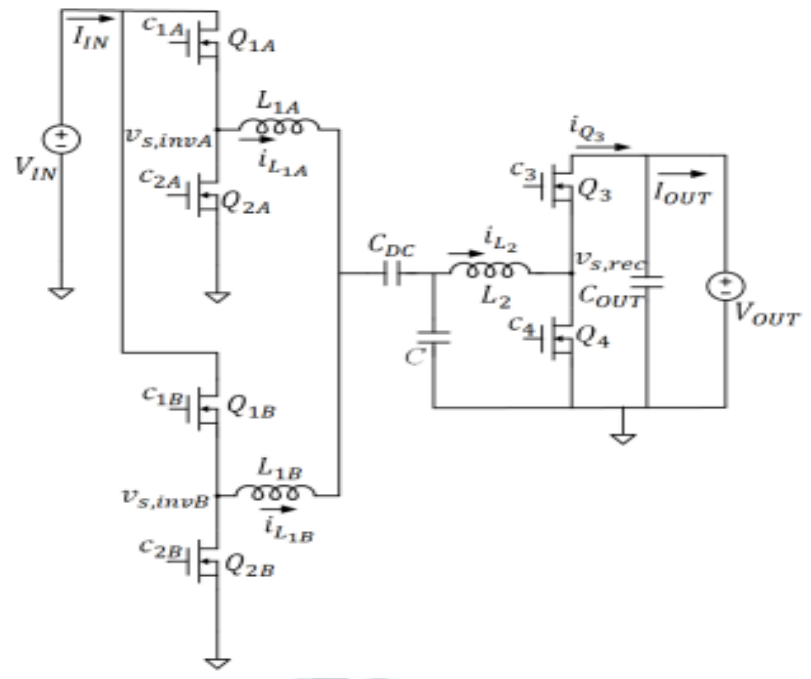

Fig 1: Wide-range LCL-T (WR-LCL-T) resonant converter

\section{RELATED WORK}

High-power light-discharging diodes (LEDs) are starting to stand out for their extra, extraordinary relationships with LED gauges. Nowadays, these LEDs are intended to achieve 10-100 lumens for each LED with higher efficiencies than incandescent and halogen bulbs. After carefully recognizing the catalyst for the advancement of high-power LEDs and examining the forthcoming markets, we portray the cutting edge amazing LED-era and the previous challenging conditions for fostering the advanced "stable realm" lamp. "We show the loop performance. And the authenticity of the super-fueled shading and white LEDs and the outcomes from over 100 white LED lamp lumens, which is a steady state representative of Thomas Edison's 20watt incandescent lamp. [1]

The generation of steady-state lighting based on SSL-LEDs is the fastest growing era, set to launch common lighting packages. The key to this technology fulfilling the promise of standard lighting is to focus on the limitations imposed by some of the most effective and most powerful lamp design options, chips and materials. Measuring these limitations is based on physical fashions and hypotheses about the relationship between circuit design and overall performance. These user-friendly barriers do not provide temporary guidance to lamp, foil and materials technologists, but improve the fashions and physical predictions developed by semiconductor scientists. [2]

Bright LED bulbs are very promising for outdoor lighting, project lights and decorative lights as well as many lighting applications for aircraft such as automation and car headlights. The purpose of this paper is to examine the answers to these LEDs. Here, the device-to-board thermal mapping is performed to the device grade and the augmentation work is completed to determine the ideal thermal performance. Each forced and herbal convection was explored and the results were subtracted for all possibilities in this particular application. [3]

The first LED diode was created in 1969, then they realized a continuous improvement in lighting efficiency and power dissipation and achieved modern InGaN devices with white colors, respectively. Skilled advances in both luminescent performance and electrical scattering have stimulated the automotive enterprise's lighting fixture programs, offering many benefits ranging from reduced reaction time to brake lights to a working lifestyle. On the other hand, tensions in luminescent performance and power dissipation give rise to most signaling devices using only a few emissions. In view of the above points, it is proposed that this represents a variation in terms of luminous performance under certain conditions. [4]

Force is provided, with another hyper-performance light-discharging diode (LED) and an organic LED. The LED wire is cut into two parts. The primary LED string 
is fueled by a conventional DC-to-DC converter, while the 2D LED wire is wired in series associated with the approaching DC current. Force was added to the subsequent LED wire without going through the dc-dc converter, consequently further developing framework proficiency. The relationships gave show that the overall circuit performance is just reliably better compared to that of the transformer. The operation of the new high-effectiveness framework has been audited and another superior circuit has been booked to give a $3 \%$ advance on the vehicle conveying the new voltage of 14 volts [5]

With lighting accounting for a significant portion of electricity consumption in the commercial quarter, modern energy-efficient lamp systems are a completely new primary interest. A good technology constant-state lamp era capable of being used in special electric-capacity lamp assemblies. There are a number of reasons why strobe state lights may be particularly useful for new programs. They boast a long lifespan in the order of hundreds of contemporary hours. Combined with the inherent rigidity of the state's powerful tools, this suggests the benefit of less conservation programs. Quick response times are also ideal for a small number of packages. This overview reviews the solid-state semiconductor lamp era, with a focal point on such software efficiency and power performance and brightness issues. Modern supply in steady state is defined in modern times: LED, laser diode, large incandescent diodes and electromagnetic diodes. Their working characteristics are mentioned and subsequent applications are described: incandescent signs and features, exit signs, site visitor lighting matches, airport runway lighting, imaginary and insight sensor lighting, floodlights, reactive and adaptive fast lights and optical fiber-guided lighting matches.[6]

The new Graces introduced with the help of the digital version of the LED attracted a lot of attention and precipitated the small and extensive software tool in place of the traditional lights. The growing trend of LED software in automated lighting fixtures can be very obvious. In this article, the design of personal car brake lighting device using LED was developed and some of the advantages of the proposed system are emphasized [7].

A singular single-transfer 3-degree (TL) dc-dc converter for PWM control of LED lighting is offered. Considering the machine efficiency and load ripple current into attention, conventional improved LED driver always operates extra energetic switch for control purposes but, the proposed converter has triumph over the control manage issue with best one switch through exploiting the "synchronous" PWM control approach, subsequently decrease the gadget value. moreover, in comparison with the same old TL enhance converter, the proposed system no longer handiest managed the gain of using a decrease voltage score electricity transfer that is half of the rated load voltage, however also removes one energetic transfer and its related driving circuit. The working principle and control scheme of the proposed TL dc-dc converter is defined in detail. A prototype of eleven-W controllable LED riding converter has been carried out to confirm the design and evaluation. The experimental end result suggests that the single-transfer TL increase converter is able to adjust the LED present day from 0 to the nominal 350 $\mathrm{mA}$ with fast batched rate. A peak performance of $95 \%$ changed done with $400 \mathrm{kHz}$ switching frequency [8].

\section{DIFFERENT TOPOLOGIES OF AC-DC CONVERTER}

For an ultra-fast charging station with an integrated battery energy storage system, suitable power electronic converter topologies for the AC-DC grid interface.

The topology of the bidirectional isolated AC-DC converter is shown in the Figure 2.

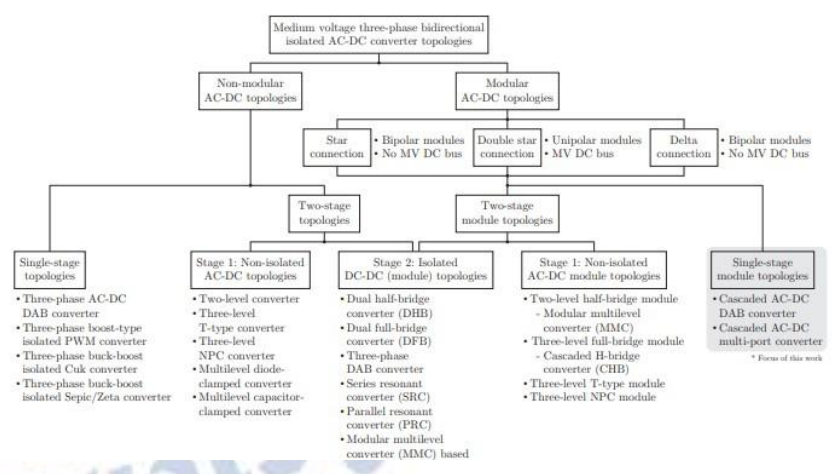

Fig 2: Topologies of bidirectional isolated AC-DC

A. Non-modular AC-DC topologies

In low voltage $(\mathrm{LV})$ applications the use of traditional -degree or 3-degree 3-section structure of AC-DC converters is pretty commonplace. Their non-modular property does no longer permit a chain of converters at the AC terminals to percentage the potential difference across numerous terminals. inside 
MV AC grid, appropriate excessive energy semiconductors ought to be engaged in such models. The two stage AC-DC converter is as shown in the Figure 3.

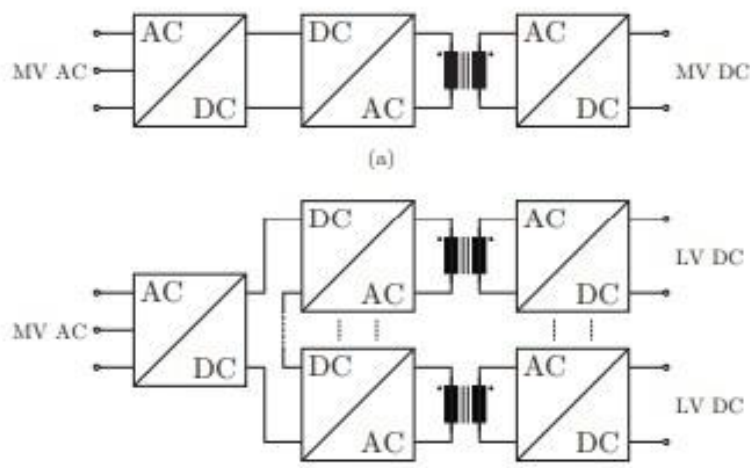

(b)

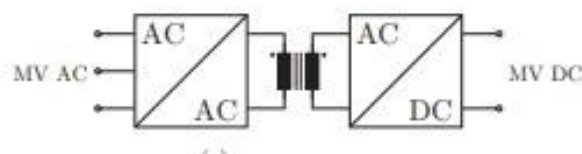

(c)

Fig 3: AC-DC converter.

\section{B. Non-isolated AC adapter}

For low voltage and low power applications, two or three level AC transformers are very common.

For medium voltage applications, these structures require high-resistance semiconductor devices with high resistive voltages (several kilovolts) and reasonable current capacity. Using a series connection of semiconductor devices controlled by the same gate signal increases the blocking voltage capacity. In multi-level transformers, the shielding voltage required for semiconductor devices is reduced by increasing the number of voltage levels. Furthermore, the harmonic content decreases as more levels become available to create stair effort. A common multi-level AC transformer topology that can form the popular (neutral point-mounted) and capacitor (flying capacitor) topology. With the increasing number of voltage levels, the hardware complexity rises in terms of a high number of switches, diodes/capacitors and gate drives. Also the commutation paths get more critical as lead inductances of the semiconductor devices connected in series add up. Moreover, the number of redundant switching states grows which leads to an increased complexity in selecting the switching states. In the end, for a relatively high number of levels, these multilevel topologies are not practical to implement (the typical limit is seven or nine levels).
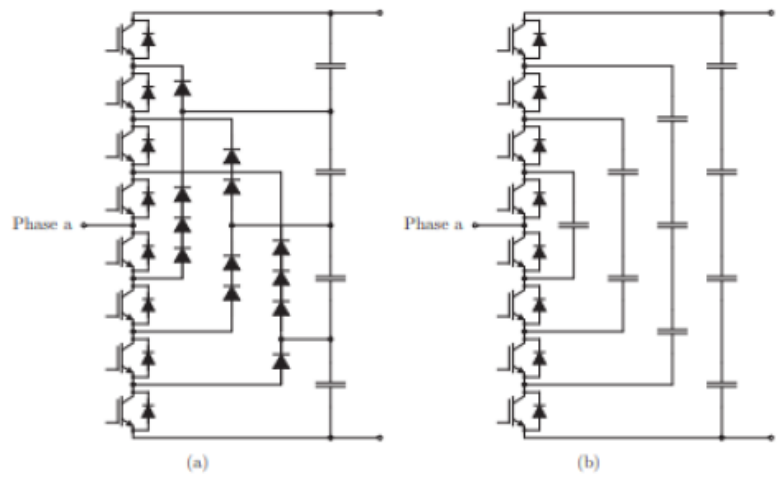

Fig 4: Generalized multilevel AC-DC converter topology

\section{Isolated DC-DC converter}

In high-power isolated two-way DC-DC power conversion, dual active bridge (DAB) inverters are widely used. The above structures are shown above and include a single-phase transformer with a half duplex bridge (DHB) transformer and a DC splitter input / output, a complete duplex bridge (DFB) transformer with a transformer as well as a three-phase transformer.

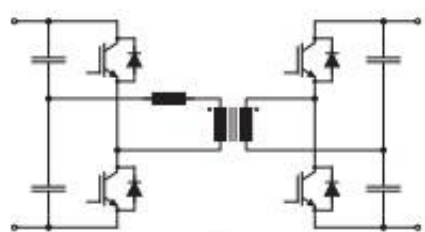

(a)

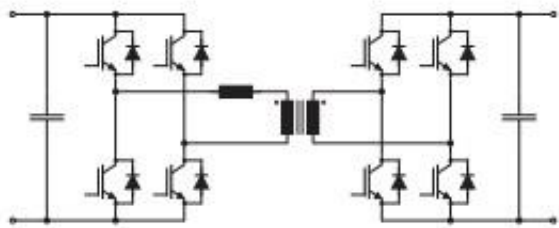

(b)

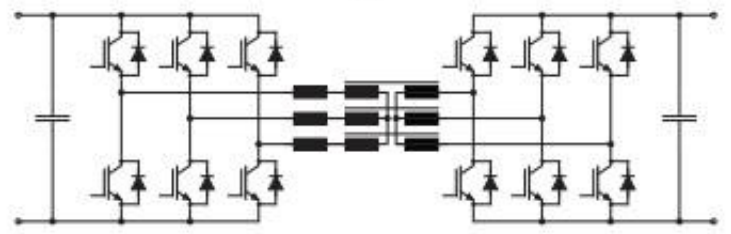

Fig 5: (a) Double-bridge (DHB) transformer with single-phase transformer (b) transformer Complete duplex bridge (DFB) transformer (c) Three-phase double active transformer (DAB) transformer related.

\section{MOSFET AS SWITCH IN CIRCUIT DESIGN}

The MOS (Metal Oxide Semiconductor) discipline impact Transistor (MOSFET) is a switching device used to make bigger or transfer electronic indicators. it's miles a unipolar, unidirectional, voltage managed device. The symbol of MOSFET is shown under 


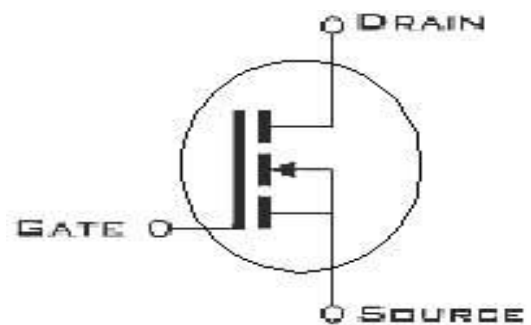

Fig 6: Symbol of MOSFET

\section{A. Operation mode}

The circuit includes a half bridge arrangement of MOSFET devices to form inverter possessing a high frequency (HF) resonant setup. A HF transformer offers both increase/decrease in voltage parameters and also isolation among the source and load. The resonant tank circuit is operated using the both rectangular waveforms of voltage or cutting-edge from the inverter circuit. The voltage measured or contemporary inside the resonant elements is changed mostly at the frequency in which the resonance occurs and via modifying the frequency around the resonance, the resonant voltage on designed elements may be modified to any requirement. via rectifying the voltage, a DC component of voltage is received. The DC voltage can either be expanded or reduced. As a result this converter be operated as step-up or step-down converter Within the gift work, step-down converter is used.

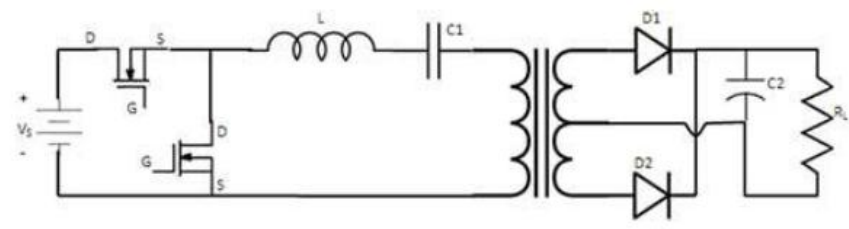

Fig 7: Circuit Operation.

\section{B. Driving Pulse for the MOSFET}

Here the driving pulse for MOSFET is shown above the first MOSFET (M1) on state at the same time second MOSFET (M2) is off state

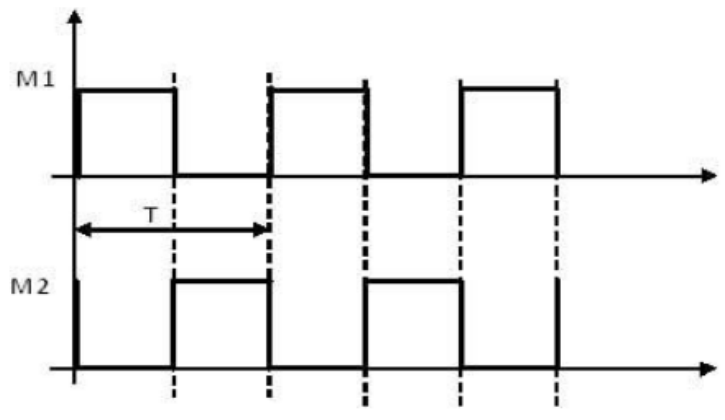

Fig 8: Driving pulse for the MOSFET.

\section{DESIGN OF THE TANK CIRCUIT AND LCL CONTROLLER}

The proposed system consists of two Half bridges and an LCL resonant tank circuit in between the bridges. The topology of the proposed system is provided below

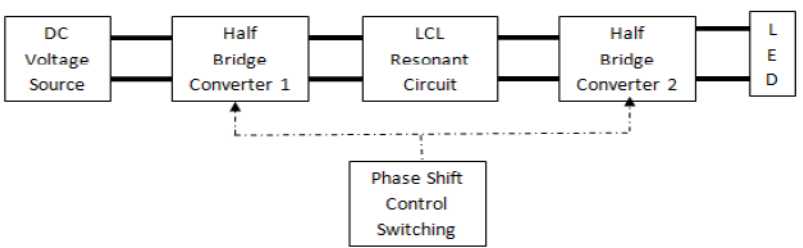

Fig 9: Block Diagram of the proposed system.

The inverter's 1/2-bridge construction transforms DC battery power and current to high-frequency $\mathrm{AC}$ voltage and current. At the specifically designed switching frequency of the LCL-T resonant network, this modified AC voltage has a capacitor parallel to the LCL-T resonant circuit + JX's inductance rating and the matching impedance of -JX. The output AC is presently rectified and fed to a string of LEDs using high-frequency based rectifier circuits.

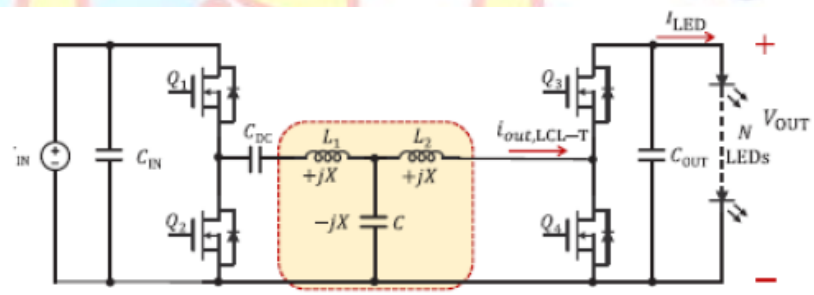

Fig 10: LCL-T Resonant circuit

The source side current flow through the rectifier circuit, which is computed for the LCL-T structured resonant converter, may be given as:

$i_{\text {out }, L C T-T}=\frac{2 V_{\text {in }}}{\pi X} \sin \left(w_{s} t-\frac{\pi}{2}\right)$

The resonant circuit lags after the inverter voltage and is neutral to the load voltage (Vout) of the proposed converter thanks to the current $90 \mathrm{o}$ of the LCL-T development. Thus, the load current is autonomous of the converter's load voltage, allowing for a broad variety of LEDs

This LED present day ILED is stated as: if the rectifier parts work inside a 90-degree portion interval with praises from the matching inverter exchanging segments,

$i_{\text {out }, \varnothing=90}=\frac{2 V_{\text {in }}}{\pi^{2} X}$

The phase-shift variation between the rectifier and the inverter switch of the LCL-T resonant converter is used 
to convert the LED current to any desired value in this mode of operation. The LED load current to be calculated as a section-shift characteristicis:

$$
I_{\mathrm{LED}}(\phi)=\frac{2 V_{\mathrm{IN}}}{\pi^{2} X} \sin \phi \stackrel{\text { def }}{=} I_{\mathrm{LED}, \max } \sin \phi .
$$

\section{A. LCL converter Design}

The capacitor is constructed using the following equation

$$
C=\frac{I_{0} * D}{\Delta V_{c} * F_{s}}
$$

The inductor value can be calculated from the following equation

$F_{o}=\frac{1}{2 * \pi \sqrt{L * C}}(4)$

\section{IMPLEMENTATION}

The simulation circuit of the lc3l converter is provided below

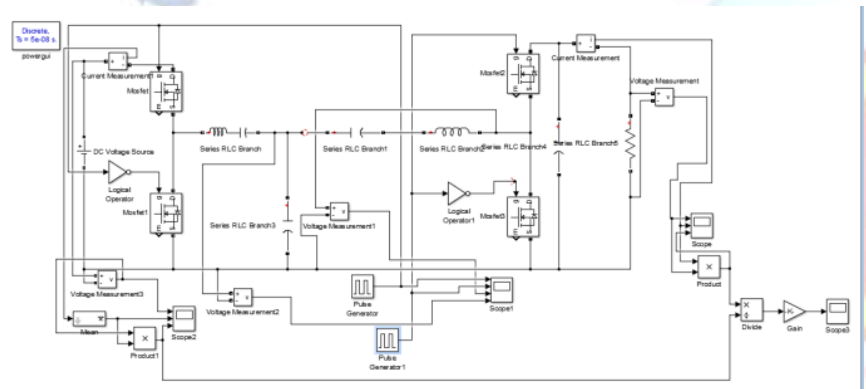

Fig 11: Simulation circuit of the Proposed converter.

The simulation circuit of lcl-T converter is provided below:

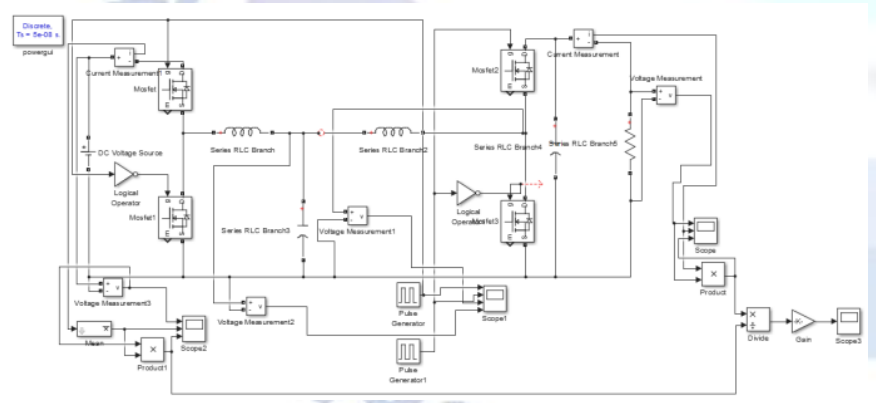

Fig 12: Simulation Circuit of LCL-T converter.

\section{RESULT AND DISCUSSION}

\section{A. Proposed Model}

In this, the input voltage is around $18 \mathrm{~V}$ and the output voltage is around $45 \mathrm{~V}$ with load power of $20 \mathrm{~W}$. The switching frequency of the above converter is $2 \mathrm{MHz}$. The inductor and capacitor values are $1.2 \mu \mathrm{H}$ and $0.01 \mu \mathrm{F}$ respectively. The pulses and voltage waveforms are provided for the Lc3L converter is shown below

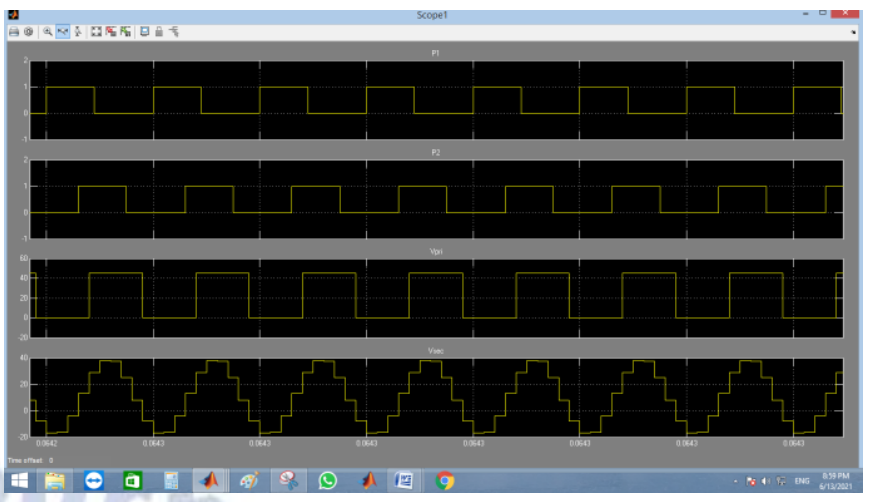

Fig 13: Pulse and voltage waveform of Lc3L converter.

In this, the switches S1 and S2 are turned ON using the Pulses P1 and P2 shown above. The S3 and S4 operates in complement to S1 and S2 when i.e S1 is ON, S3 will be OFF and when S1 is OFF, S3 will be ON.

The input voltage, current and power waveforms are shown below: In this, the input voltage is around $18 \mathrm{~V}$ and current is around 1.2A.

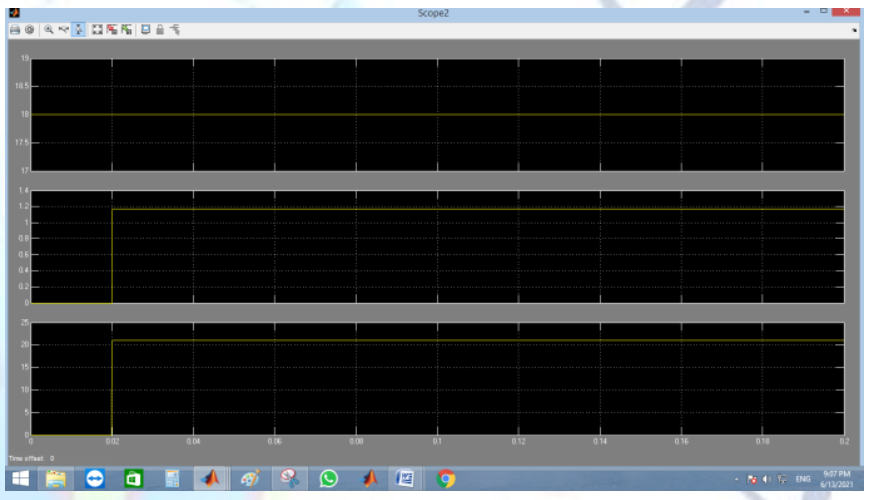

Fig 14: The voltage, current and power waveform of Lc3L converter The output voltage, current and power waveforms are provided below:In this, the load voltage is around $45 \mathrm{~V}$ and current is around $0.45 \mathrm{~A}$.

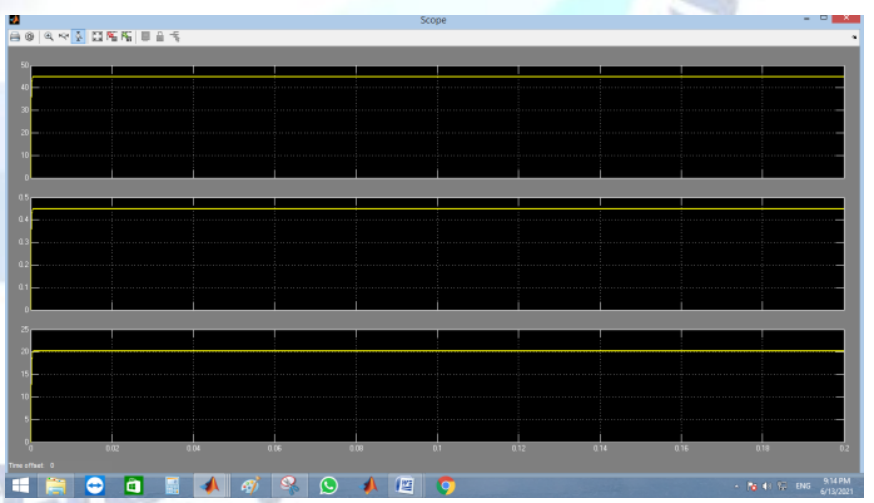

Fig 15: The voltage, current and power waveform of Lc3L converter The efficiency waveform of the lc3l converter is provided in below figure. The efficiency of 1c31 converter is around $96.5 \%$. 


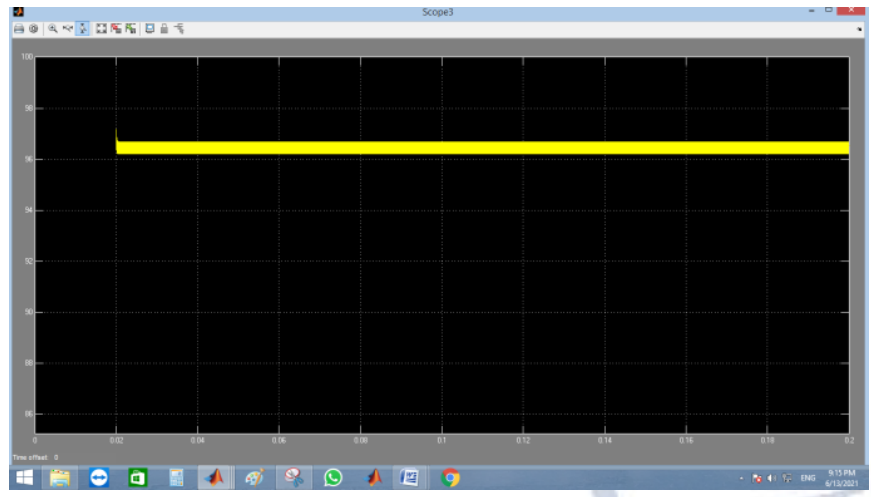

Fig 16: Efficiency waveform of Lc3L converter

\section{B. LCL-T converter}

The input voltage, current and power waveforms are shown in below figure, in this, the input voltage is around $18 \mathrm{~V}$ and current is around $1.2 \mathrm{~A}$.

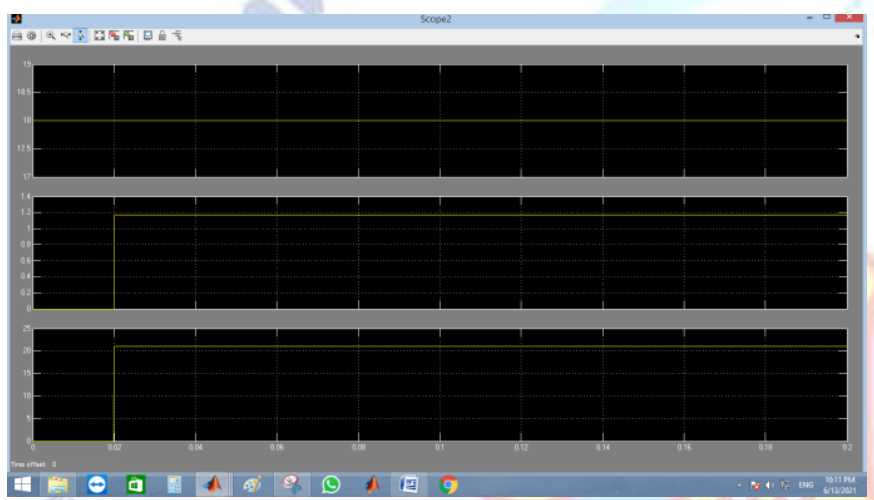

Fig 17: Input voltage, current and power waveform of LCL-T converter

The output voltage, current and power waveforms are provided in below figure, the parameters are the load voltage is around $45 \mathrm{~V}$ and current is around $0.45 \mathrm{~A}$.

The efficiency of the LCL converter is $98.5 \%$ and the same is provided below,

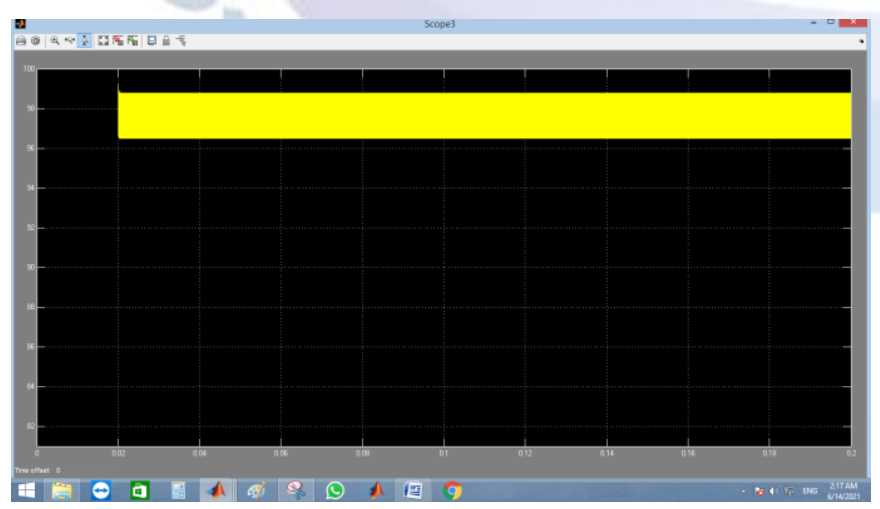

Fig 18: Efficiency waveform of LCL converter

\section{CONCLUSION}

This paper proposes the most efficient controlled LCL-T motor based on the DC-DC converter. The operation of the proposed transformer was thoroughly examined and the design of the proposed transformer was also included in this study. For different load voltages, phase shift control is used to manage the load current. For LED driving applications, the LCL-T structural resonant DC-DC transformer has been compared to the LC3L structured DC-dc resonant transformer. The proposed LCL-T switch has about 98.5 percent efficiency, while the LC3L has 96.5 percent efficiency.

\section{REFERENCES}

[1] E. D.A. Steigerwald, J.C. Bhat, D. Collins, R.M. Fletcher, M.O. Holcomb, M.J. Ludowise, P.S. Martin, S.L. Rudaz, "Illumination with Solid State Lighting Technology," IEEE Journal of Selected Topics in Quantum Electronics, vol. 8, no. 2, pp. 310-320, August 2002.

[2] J.Y. Tsao, "Solid-State Lighting: Lamps, Chips, and Materials for Tomorrow," IEEE Circuits and Devices Magazine, vol. 20, no. 3, pp.28-37, May/June 2004.

[3] Y. Lai and N. Cordero, "Thermal Management of Bright LEDs for Automotive Applications," Proceedings of the International Conference on Thermal, Mechanical and Multiphysics Simulation and Experiments in Micro-Electronics and Micro-Systems (EuroSime), Como, Italy, April 2006.

[4] D. Gacio, J. Cardesin, E.L. Corominas, J.M. Alonso, M. Dalla-Costaand A.J. Calleja, "Comparison Among Power LEDs for Automotive Lighting Applications," IEEE Industry Applications Society Annual Meeting, Edmonton, Alta., October 2008.

[5] A. Pollock, H. Pollock and C. Pollock, "High Efficiency LED Power Supply," IEEE Journal of Emerging and Selected Topics in Power Electronics, vol. 3, no. 3, pp. 617-623, September 2015.

[6] S. Peralta and H. Ruda, "Applications for Advanced Solid-State Lamps," IEEE Industry Applications Magazine, vol. 4, no. 4, pp. 31-42, August 1998.

[7] Y.C. Lin, H.Y. Wang and W.J. Cheng, "A Novel Vehicle Brake Light System," Proceedings of the International Conference on Intelligent Information Hiding and Multimedia Signal Processing (IIH-MSP), Kyoto, Japan, September 2009.

[8] C. Zheng, W. Yu, J.S. Lai and H. Ma, "Single-Switch Three-Level Boost Converter for PWM Control LED Lighting," Proceedings of the IEEE Energy Conversion Congress and Exposition (ECCE), Phoenix, AZ, September 2011.

[9] L. Feng, Y. Zhou, Y. Peng and W. Li, “A New Analog Control Circuit used in LED Driver," Proceedings of the IEEE International Conference on Solid-State and Integrated Circuit Technology(ICSICT), Guilin, china, October 2014.

[10] A. Sepahvand, M. Doshi, V. Yousefzadeh, J. Patterson, K.K. Afridi and D. Maksimović, "Automotive LED Driver Based on High Frequency Zero Voltage Switching Integrated Magnetics Ćuk Converter," Proceedings of the IEEE Energy Conversion Congress and Exposition (ECCE), Milwaukee, WI, September 2016. 